\title{
ANALISIS PERHITUNGAN DAN PERBANDINGAN BIAYA OPERASIONAL KENDARAAN (BOK) MEDIUM BUS TYPE J 05 123 CC DENGAN BIG BUS TYPE J 08 E - UF (Koridor 1 Pakupatan - Serang Timur - Serang Barat)
}

\author{
Roselina Rahmawati \\ Jurusan Teknik Sipil, Politeknik Negeri Semarang, JL. Prof. Soedarto, Tembalang, Semarang, Jawa \\ Tengah, 50275, email: Roselina.rahmawati@polines.ac.id
}

\begin{abstract}
ABSTRAK
Angkutan umum antar kota dalam propinsi adalah salah satu dari banyak jenis transportasi umum yang digunakan mengangkut penumpang dari satu kota ke kota lain di dalam sebuah provinsi. Transportasi ini merupakan urat nadi kehidupan berbangsa dan bernegara, yang mempunyai fungsi sebagai penggerak dan penunjang pembangunan serta sistem yang terdiri dari sarana dan prasarana, yang didukung oleh tata laksana dan sumber daya manusia membentuk jaringan prasarana dan jaringan pelayanan. Penelitian dilakukan dengan mengumpulkan data primer dan data sekunder kemudian dianalisis dengan metode dari literatur, jurnal, dan penelitian terdahulu yang terkait dengan biaya operasi kendaraan. Biaya operasi kendaraan dibagi atas menjadi 3 kelompok yaitu biaya tetap (fixed cost), biaya tidak tetap (running cost), biaya overhead. Hasilnya menunjukkan bahwa biaya operasional setiap kendaraan bervariasi sesuai dengan tipe kendaraan yang digunakan. Biaya operasional kendaraan di di Cilegon, Serang, Pandeglang, dan Rangkasbitung (koridor 1 Pakupatan - Serang Timur - Serang Barat) untuk medium bus tipe J 05123 cc adalah Rp. 8.577/ Km dan untuk bus besar tipe J $08 \mathrm{E}$ - UF adalah Rp. 9.817/Km. Hasil analisis dari segi perawatan bus bus medium tipe $\mathrm{J} 05123 \mathrm{CC}$ lebih besar dari bus besar tipe $\mathrm{J} 08 \mathrm{E}-\mathrm{UF}$.
\end{abstract}

Kata kunci: BOK, Angkutan umum, Kota Serang

\begin{abstract}
Public transportation between cities within the province is one of the many types of public transportation that is used to transport passengers from one city to another in a province. This transportation is the lifeblood of the nation and state life, which has the function as an activator and a supporter of development and a system consisting of facilities and infrastructure, which is supported by governance and human resources to form infrastructure and service networks. The research was conducted by collecting primary data and secondary data; then, analyzed with methods from the literature, journals, and previous research related to vehicle operating costs. Vehicle operating costs are divided into 3 groups, namely fixed costs, running costs, overhead costs. The results show that the vehicle operating cost of each vehicle is according to the type of vehicle used. Vehicle operating costs at Cilegon, Serang, Pandeglang and Rangkasbitung (corridor 1 Pakupatan - East Serang - Serang Barat) for medium bus type J $05123 \mathrm{cc}$ is Rp. 8, 577 / Km and for big bus type J $08 \mathrm{E}-\mathrm{UF}$ is Rp. 9, 817 / Km. The results for analysis of-maintenance of medium bus type J 05123 CC is greater than big bus type J 08 E - UF.
\end{abstract}

Keywords: Vehicle Operationg Cost, Public Transportation, Serang City

\section{PENDAHULUAN}

Transportasi merupakan urat nadi kehidupan berbangsa dan bernegara, yang mempunyai fungsi sebagai penggerak, pendorong dan penunjang pembangunan serta sistem yang terdiri dari sarana dan prasarana, yang didukung oleh manajemen dan pola ketersediaan sumber daya manusia untuk membentuk jaringan prasarana dan jaringan pelayanan. Transportasi juga mempunyai posisi penting dan strategis sehingga perlu 
ditata dalam suatu sistem yang dapat memadukan serta mewujudkan transportasi dengan tingkat kebutuhan dan tingkat pelayanan yang tertib, aman, nyaman, cepat, teratur, lancar serta dengan biaya yang terjangkau.

Sarana transportasi yang paling penting untuk mendukung aktivitas dan mobilitas penduduk sehari-hari disuatu perkotaan adalah angkutan umum. Positif negatifnya keadaan angkutan umum dan transportasi pada umumnya disuatu perkotaan merupakan cerminan baik buruknya sistem kota tersebut. Kondisi pelayanan angkutan umum di Kota-kota di Provinsi Banten terutama di wilayah Kabupaten dan Kota Serang sudah sangat memprihatinkan. Hal ini terlihat dari dominasi angkutan berkapasitas kecil yang menambah kepadatan dan kesemrawutan lalu lintas. Kondisi ini semakin diperparah oleh perilaku pengemudi yang ugal-ugalan karena berebut penumpang sehingga aspek kenyamanan dan keselamatan penumpang menjadi terabaikan.

Sebagai ibukota Provinsi Banten, Wilayah Cilegon, Serang, Pandeglang, dan Rangkasbitung mempunyai tingkat pertumbuhan penduduk dan mobilitas perekonomian yang berkembang sangat cepat seiring dengan tingkat pembangunan yang terus meningkat, hal tersebut perlu diimbangi dengan pelayanan jasa angkutan yang berkualitas dan berbasis angkutan massal, untuk itu dalam rangka memberikan pelayanan kepada masyarakat perlu dilakukan tindakan nyata dalam menyusun perencanaan, pengaturan dan pengendalian sistem transportasi di Wilayah Cilegon, Serang, Pandeglang, dan Rangkasbitung.

Adapun tujuan dari analisa ini adalah untuk mengetahui berapa biaya operasional kendaraan $(\mathrm{BOK})$ di Koridor 1 rute Pakupatan - Serang Timur - Serang Barat khususnya jenis Medium Bus Type J 05123 CC dan Big Bus J 08E-UF. Dan manfaat yang diharapkan yaitu agar hasil dari analisa ini dapat dijadikan pertimbangan bagi pemerintah dalam menetapkan jenis kendaraan yang akan di operasikan pada koridor tersebut.

\section{TINJAUAN PUSTAKA}

Pengertian Biaya Operasi Kendaraan Biaya operasi kendaraan di definisikan sebagai biaya dari semua faktor faktor yang terkait dengan pengoperasian satu kendaraan pada kondisi normal untuk suatu tujuan tertentu. Berdasarkan pertimbangan ekonomi, diperlukan kesesuaian antara besarnya tarif (penerimaan). Dalam hal ini pengusaha mendapatkan keuntungan yang wajar dan dapat menjamin kelangsungan serta perkembangan usaha jasa angkutan umum yang dikelolanya. Komponen biaya operasi kendaraan dibagi dalam 3 kelompok, yaitu biaya tetap (Standing Cost), biaya tidak tetap (Running Cost) dan biaya overhead.

A. Biaya Tetap (Standing Cost)

Biaya tetap adalah biaya yang dalam pengeluarannya tetap tanpa tergantung pada volume produksi yang terjadi. Biaya tetap ini dapat dikelompokkan sebagai berikut:

a. Biaya modal kendaraan (BM): Para pengusaha angkutan antar kota dalam propinsi sebagian besar memilih system pemilikan kendaraan dalam sistem kredit beserta bunga yang harus dilunasi dalam jangka waktu tertentu. 
Pembayaran kredit ini dilakukan dengan cara membayar dengan jumlah tertentu dan tetap setiap tahun, yang terdiri dari pembayaran kembali baik bunga maupun pinjaman pokok sekaligus.

b. Biaya penyusutan (BP) Biaya penyusutan yaitu biaya yang dikeluarkan untuk penyusutan nilai kendaraan karena berkurangnya umur ekonomis. Biaya depresiasi dapat diperlakukan sebagi komponen dari biaya tetap, jika masa pakai kendaraan dihitung berdasarkan waktu. Untuk menghitung biaya depresiasi, hal pertama yang dilakukan adalah menentukan harga kendaraan. Biaya penyusutan dapat dihitung dengan cara sebagai berikut:

$$
\mathrm{D}=\frac{(P-L)}{n}
$$

Dimana :

$\mathrm{D}=$ Penyusutan pertahun

$\mathrm{P}=$ Harga kendaraan baru

$\mathrm{L}=$ Nilai sisa kendaraan bekas (20\% dari harga baru)

$\mathrm{n}=$ Umur ekonomis

\section{c. Biaya Upah}

Biaya awak adalah biaya yang dikeluarkan perusahaan kendaraan oleh pemilik kendaraan bermotor (jenis komersial), untuk membayar upah kru (pengemudi dan pembantu/kernet). Perhitungan biaya ekonomi awak kendaraaan ini dilakukan dengan mengikuti metode yang digunakan oleh HOFF \& OVERGAARD (1992), dimana dalam perhitungan biaya juga telah memasukkan biaya direct overhead sebesar $25 \%$.

B. Biaya Tidak Tetap (Running Cost)

Biaya tidak tetap merupakan biaya yang dikeluarkan pada saat kendaraan beroperasi. Komponen biaya yang termasuk ke dalam biaya tidak tetap ini adalah :

a. Biaya Bahan Bakar (BBM)

b. Biaya Pemakaian Ban ( PB )

c. Biaya Perawatan dan Perbaikan Kendaraan ( PP )

C. Biaya Overhead

Beberapa peneliti melakukan dengan 2 (dua) cara yaitu:

a. Menghitung 20-25\% dari jumlah biaya tetap dan biaya tidak tetap.

b. Menghitung biaya overhead secara terperinci, yaitu menghitung biaya overhead yang perlu terus dipantau secara berkala oleh pemilik kendaraan.

Jadi biaya overhead total (Rp/tahun):

$\mathrm{BOV}=20 \% \times \mathrm{BOK}$ (/Tahun)

Dimana :

$\mathrm{BOV}=$ Biaya Overhead

BOK = Biaya Tetap + Biaya Variabel atau Biaya Tidak Tetap 


\section{METODE PENELITIAN}

Data dan informasi yang didapat dianalisis secara kuantitatif dengan menggunakan metode perhitungan BOK dengan metode dari literatur, jurnal, dan penelitian terdahulu yang umumnya dengan melakukan pengelompokan komponen diatas menjadi 3 kelompok yaitu biaya tetap (fixed cost), biaya tidak tetap (running cost), biaya overhead. Adapun gambar bagan alir penelitian dapat dilihat berikut ini:

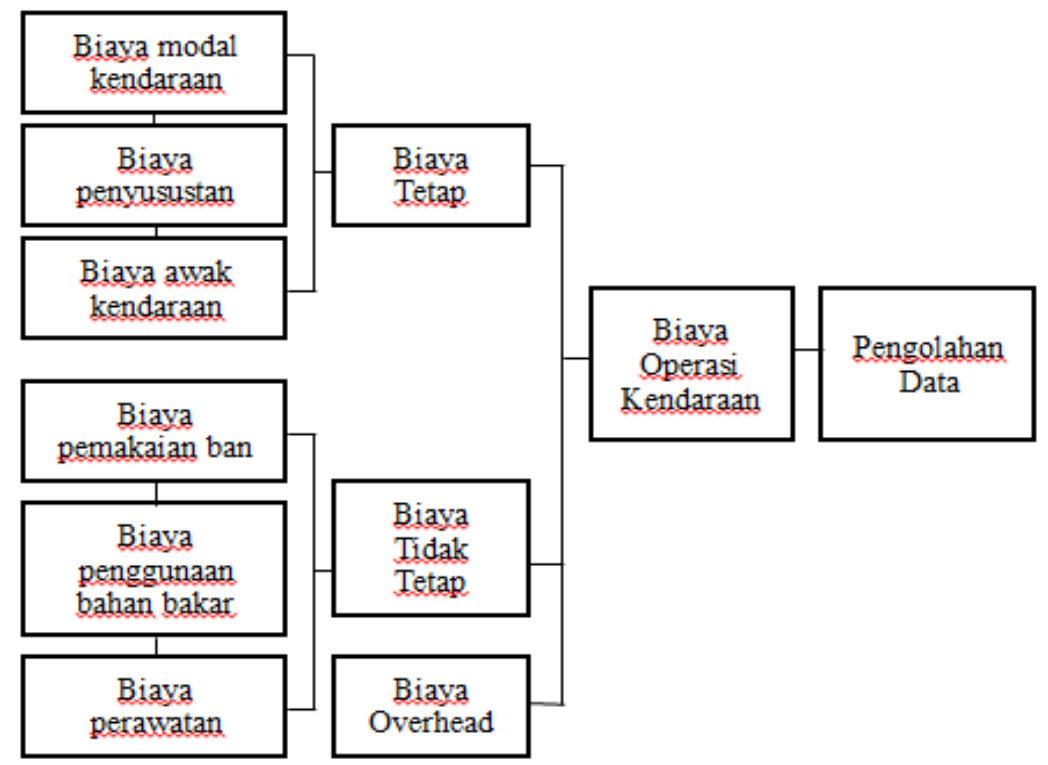

Gambar 1. Bagan Alir Analisis Data

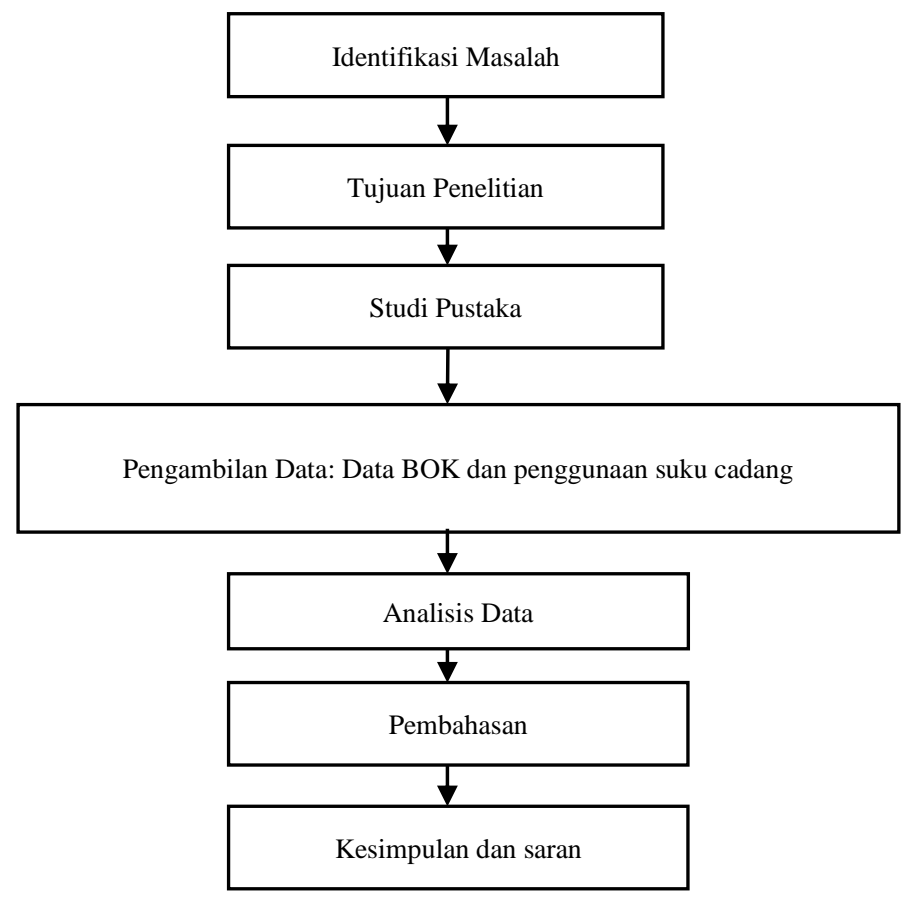

Gambar 2. Bagan Alir Penelitian 


\section{HASIL DAN PEMBAHASAN}

\section{Data bus}

Berikut Tabel data bus dalam penelitian ini

Tabel 1. Data Umum Bus

\begin{tabular}{|c|c|c|}
\hline \multirow[t]{2}{*}{ Uraian Karakterisitik } & \multicolumn{2}{|c|}{ Data Bus yang beroperasi di Koridor 1} \\
\hline & $\begin{array}{c}\text { Medium Bus Type J } 05 \\
123 \text { CC }\end{array}$ & Big Bus J 08E-UF \\
\hline Harga Kendaraan (Rp.) & 659.600 .000 & 850.000 .000 \\
\hline Kapasitas penumpang & 30 & 80 \\
\hline Bahan Bakar & Solar & Solar \\
\hline Kapasitas Tangki (Liter) & 240 & 270 \\
\hline
\end{tabular}

\section{Data biaya operasi kendaraan}

a. Harga Bahan Bakar

Unit biaya ekonomi bahan bakar dihitung dengan menjumlahkan biaya-biaya yang dikeluarkan selama proses produksi, mulai dari bentuk bahan mentah hingga menjadi bahan bakar minyak, yang informasinya diperoleh dari pertamina untuk bahan bakar solar adalah sebesar Rp. 8000/ Liter

b. Harga Bahan Pelumas

Untuk jenis kendaraan bis kecil dan besar menggunakan pelumas Fastron dengan harga Rp. 60.000/ Liter. Pelumas Gardan Rp. 40.000/ Liter. Pelumas Transmisi Rp. 30.600/ Liter

c. Harga Ban

Untuk jenis kendaraan bis kecil dan besar menggunakan ban dengan harga Rp. 4.000.000 untuk bis kecil dan Rp. Untuk bis besar Rp.5.500.000

d. Biaya Upah

Biaya Upah adalah biaya yang dikeluarkan perusahaan kendaraan oleh pemilik kendaraan bermotor (jenis komersial), untuk membayar upah kru (pengemudi dan pembantu/kernet). Perhitungan biaya upah kendaraaan ini dilakukan dengan mengikuti metode yang digunakan oleh HOFF \& OVERGAARD (1992), dimana dalam perhitungan biaya juga telah memasukkan biaya direct overhead sebesar $25 \%$. Hasil perhitungan biaya upah kendaraan tersebut dapat dilihat pada tabel berikut.

Tabel 2. Data Upah Kendaraan

\begin{tabular}{lc}
\hline \multicolumn{1}{c}{ Pekerja } & Upah (Rp.) \\
\hline a. Supir Bis & $3,000,000.00$ \\
b. Operator & $2,500,000.00$ \\
c. Kernet Bis/security & $2,000,000.00$ \\
d. Staff halte & $2,000,000.00$ \\
\hline
\end{tabular}

\section{Pengolahan dan analisis data BOK untuk medium bus tipe J 05123 cc}

Karakteristik operasional:

a. Round trip / hari $=12$ Putaran

b. Panjang round trip koridor $1=19 \mathrm{~km}$

c. Total panjang lintasan perhari $=19$ x $12=228 \mathrm{~km} / \mathrm{hari}=68.400 \mathrm{~km} / \mathrm{tahun}$ (dihitung 300 hari kerja) 


\section{Biaya Tetap}

1) Biaya Modal Kendaraan

Harga baru kendaraan $=$ Rp. 659.600.000,-

Umur ekonomis kendaraan $=5$ Tahun

- Biaya modal kendaraan per tahun $=659.600 .000: 5=$ Rp. 131.920 .000

- Biaya modal kendaraan per $\mathrm{Km}=131.920 .000 / 68.400$ km = Rp. 1.929

2) Biaya Penyusutan (D)

Di asumsikan :

- Nilai sisa kendaraan bekas $(\mathrm{L})=20 \%$ dari harga baru

- Umur ekonomis kendaraan (n) $=5$ Tahun

Dengan menggunakan rumus penyusutan kendaraan

$=\frac{(659.600 .000-(20 \% \times 659.600 .000))}{5}$

$\mathrm{D}=\mathrm{Rp} .105 .536 .000 /$ tahun

$\mathrm{D}=\mathrm{Rp} .1 .543 / \mathrm{Km}$

3) Biaya Upah

Dibutuhkan sebanyak: 2 orang supir bis (2 shift) dan 2 orang kernet. Sehingga perhitungan upah dapat dilihat sebagai berikut:

Tabel 3. Biaya kebutuhan upah

\begin{tabular}{lr}
\hline \multicolumn{1}{c}{ Pekerja } & Upah (Rp.) \\
\hline a. Supir Bis & $6,000,000$ \\
b. Kernet Bis/security & $4,000,000$ \\
\hline
\end{tabular}

Sehingga

Biaya Upah/ Bulan $=$ Rp. 10.000.000

Biaya Upah/ Tahun $=$ Rp. 120.000.000

Biaya Upah/ km = Rp. 1.754

\section{Biaya Tidak Tetap}

1) Biaya Bahan Bakar

Pemakaian BBM per hari $=23$ Liter

Harga $\mathrm{BBM}=$ Rp. 8000,-

Biaya pemakaian $\mathrm{BBM}=$ Rp. 182.400,- / Hari

$=$ Rp. 54.720.000,- / Tahun

$=$ Rp. $800,-/ \mathrm{Km}$

2) Biaya Pemakaian Ban

Daya tahan ban $=25.000 \mathrm{Km}$

Harga ban baru = Rp. 4.000.000,-

Jumlah pemakaian ban $=4$ ban

Jumlah penggantian ban per tahun $=(68.400 / 25.000) \times 4=\sim 11$ ban $/$ tahun

Biaya penggunaan ban

$=$ Rp. 4.000.000,- $\mathrm{x} 11$

$=$ Rp. 44.000.000,- / Tahun

$=$ Rp. $643.27 / \mathrm{Km}$ 
3) Biaya perawatan dan perbaikan kendaraan

a. Servis Kecil

Tabel 4. Rincian Biaya Servis Kecil

\begin{tabular}{lll}
\hline \multicolumn{1}{c}{ Item } & Kebutuhan & \multicolumn{1}{c}{ Biaya (Rp.) } \\
\hline Oli mesin & 8 liter & 480,000 \\
Oli Gardan & 3 liter & 120,000 \\
Oli Transmisi & 3 liter & 91,800 \\
Minyak Rem & 1 liter & 65,000 \\
Gemuk & $1 \mathrm{~kg}$ & 35,000 \\
Ongkos kerja & & 175,000 \\
& Total biaya & 966,800 \\
\hline
\end{tabular}

Jarak tempuh 1 kali servis kecil $=5.000 \mathrm{Km}$

Waktu servis kecil $/$ Tahun $=68.400 / 5000=14 \mathrm{kali}$

Biaya perawatan servis kecil

=Rp. 966.800,- x 14

= Rp. 13.535.200,- $/$ Tahun

$=$ Rp. 198,- / Km

b. Servis besar

Tabel 5. Rincian Biaya Servis Besar

\begin{tabular}{|c|c|c|}
\hline Item & Kebutuhan & Biaya (Rp.) \\
\hline Oli mesin & 8 liter & 480,000 \\
\hline Oli Gardan & 3 liter & 120,000 \\
\hline Oli Transmisi & 3 liter & 91,800 \\
\hline Minyak Rem & 1 liter & 65,000 \\
\hline Gemuk & $2 \mathrm{~kg}$ & 70,000 \\
\hline Saringan Udara & 1 buah & 732,000 \\
\hline Saringan Oli & 4 buah & 192,000 \\
\hline Saringan Solar & 1 buah & 154,800 \\
\hline Air aki & 2 botol & 40,000 \\
\hline Sambungan Kabel & 2 buah & 40,000 \\
\hline Lampu2 & 4 buah & $1,400,000$ \\
\hline Tak terduga & & 100,000 \\
\hline \multirow[t]{2}{*}{ Ongkos kerja } & & 350,000 \\
\hline & Total Biaya & $3,835,600$ \\
\hline
\end{tabular}

Jarak tempuh 1 kali servis besar $=15.000 \mathrm{Km}$

Waktu servis besar $/$ tahun $=68.400 / 15.000=5$ kali

Biaya perawatan servis besar

$=\operatorname{Rp} 3.835 .600 .000,-\mathrm{x} 5$

$=$ Rp. 19.178.000,-/Tahun

$=$ Rp. $280,-/ \mathrm{Km}$ 
Jadi total biaya perawatan kendaraan

$=$ Rp.32.713.200,- /Tahun

$=\mathrm{Rp} 478,-/ \mathrm{Km}$

Dari hasil perhitungan diatas maka didapatkan hasil perhitungan biaya sebagai berikut:

- Biaya Tetap Kendaraan/th Rp. 237,456,260

- Biaya Tetap Kendaraan/ km

Rp. 3,472

- Biaya Tidak Tetap Kendaraan/ th

Rp. 251,433,200

- Biaya Tidak Tetap Kendaraan/ km Rp. 3,676

- Biaya Overheadkend/ th Rp. 97,777,892

- Biaya Overheadkend/ km Rp. 1,430

Total BOK Per Tahun Rp. 586.667.352

Total BOK Per Km Rp. 8.577

\section{Pengolahan dan analisis data BOK untuk Big Bus J 08E- UF}

Karakteristik operasional:

a. Round trip / hari $=12$ Putaran

b. Panjang round trip koridor $1=19 \mathrm{~km}$

c. Total panjang lintasan perhari $=12 \times 19=228 \mathrm{~km} / \mathrm{hari}=68.400 \mathrm{~km} / \mathrm{tahun}$ (dihitung 300 hari kerja)

\section{Biaya Tetap}

1) Biaya Modal Kendaraan

Harga baru kendaraan $=$ Rp. 850.000.000,-

Umur ekonomis kendaraan $=5$ Tahun

- Biaya modal kendaraan per tahun $=850.000 .000: 5=$ Rp. 170.000 .000

- Biaya modal kendaraan per $\mathrm{Km}=170.000 .000 / 68.400 \mathrm{~km}=\mathrm{Rp} .2 .485$

2) Biaya Penyusutan (D)

Di asumsikan :

- Nilai sisa kendaraan bekas (L) $=20 \%$ dari harga baru

- Umur ekonomis kendaraan $(\mathrm{n})=5$ Tahun

Dengan menggunakan rumus penyusutan kendaraan

$=\frac{(850.000 .000-(20 \% \times 850.000 .000))}{5}$

$\mathrm{D}=\mathrm{Rp} .136 .000 .000 /$ tahun

$\mathrm{D}=\mathrm{Rp} .1 .988 / \mathrm{Km}$

3) Biaya Upah

Dibutuhkan sebanyak: 2 orang supir bis ( 2 shift) dan 2 orang kernet bis. Sehingga perhitungan upah dapat dilihat pada tabel berikut 
Tabel 6. Biaya kebutuhan upah

\begin{tabular}{lll}
\hline \multicolumn{1}{c}{ Pekerja } & Upah (Rp.) \\
\hline a. Supir Bis & $6,000,000$ & \\
b. Kernet Bis/security & $4,000,000$ & \\
\hline
\end{tabular}

Sehingga

Biaya Upah/ Bulan $=$ Rp. 10.000.000

Biaya Upah/ Tahun = Rp. 120.000.000

Biaya Upah/ km = Rp. 1.754

\section{Biaya Tidak Tetap}

1) Biaya Bahan Bakar

Pemakaian BBM per hari $=22.8$ Liter

Harga BBM = Rp. 8000,-

Biaya pemakaian BBM = Rp. 182.400,- / Hari

$=$ Rp. 54.720.000,- / Tahun

$=$ Rp. $800,-/ \mathrm{Km}$

2) Biaya Pemakaian Ban

Daya tahan ban $=30.000 \mathrm{Km}$

Harga ban baru $=$ Rp. 5.500.000,-

Jumlah pemakaian ban $=4$ ban

Jumlah penggantian ban per tahun $=(68.400 / 30.000) \times 4=10$ ban $/$ tahun

Biaya penggunaan ban

$=$ Rp. 5.500.000,- x 10

$=$ Rp. 55.000.000,- $/$ Tahun

$=$ Rp. $805 / \mathrm{Km}$

3) Biaya perawatan dan perbaikan kendaraan

a. Servis Kecil

Tabel 7. Rincian Biaya Servis Kecil

\begin{tabular}{llc}
\hline \multicolumn{1}{c}{ Item } & Kebutuhan & Biaya (Rp.) \\
\hline Oli mesin & 10 liter & 600.000 \\
Oli Gardan & 5 liter & 200.000 \\
Oli Transmisi & 5 liter & 153.000 \\
Minyak Rem & $1 \mathrm{~kg}$ & 65.000 \\
Gemuk & 1 liter & 35.000 \\
Ongkos kerja & & 225.000 \\
& Total biaya & 1.278 .000 \\
\hline
\end{tabular}

Jarak tempuh 1 kali servis kecil $=8.000 \mathrm{Km}$

Waktu servis kecil/Tahun $=68.400 / 8000=9 \mathrm{kali}$

Biaya perawatan servis kecil

= Rp. 1.278.000,- x 9

$=$ Rp. 11.502.00., $-/$ Tahun

$=\mathrm{Rp} .168,-/ \mathrm{Km}$

b. Servis besar

Berikut adalah daftar tabel kebutuhan item untuk servis besar 
Tabel 8. Rincian Biaya Servis Besar

\begin{tabular}{lll}
\hline \multicolumn{1}{c}{ Item } & \multicolumn{1}{c}{ Kebutuhan } & Biaya (Rp.) \\
\hline Oli mesin & 10 liter & 600.000 \\
Oli Gardan & 5 liter & 200.000 \\
Oli Transmisi & 5 liter & 153.000 \\
Minyak Rem & 1 liter & 65.000 \\
Gemuk & $2 \mathrm{~kg}$ & 70.000 \\
Saringan Udara & 1 buah & 732.000 \\
Saringan Oli & 4 buah & 192.000 \\
Saringan Solar & 1 buah & 154.800 \\
Air aki & 2 botol & 40.000 \\
Sambungan Kabel & 2 buah & 40.000 \\
Lampu2 & 4 buah & 1.400 .000 \\
Tak terduga & & 100.000 \\
Ongkos kerja & & 375.000 \\
& Total Biaya & 4.121 .800 \\
\hline
\end{tabular}

Jarak tempuh 1 kali servis besar $=30.000 \mathrm{Km}$

Waktu servis besar $/$ tahun $=68.400 / 30.000=3 \mathrm{kali}$

Biaya perawatan servis besar

$=\operatorname{Rp} 4.121 .800,-$ x 3

$=$ Rp. 12.365.400,-/Tahun

$=$ Rp. $181,-/ \mathrm{Km}$

Jadi total biaya perawatan kendaraan $=$ Rp.23.867.400,- $/$ Tahun = Rp. 349,- $/ \mathrm{Km}$

Dari hasil perhitungan diatas maka didapatkan hasil perhitungan biaya sebagai berikut:

- Biaya Tetap Kendaraan/th Rp. 306,000,000

- Biaya Tetap Kendaraan/ km

Rp. 4,474

- Biaya Tidak Tetap Kendaraan/ th

Rp. 253,587,400

- Biaya Tidak Tetap Kendaraan/ km

Rp. 3,707

- Biaya Overheadkend/ th

Rp. 111,917,480

- Biaya Overheadkend/ km

Rp. 1,636

Total BOK Per Tahun Rp. 671.504.880

Total BOK Per Km Rp. 9.817 


\section{KESIMPULAN}

Dari hasil penelitian diatas dapat diperoleh kesimpulan, sebagai berikut:

a. Dari hasil analisis data, harga kendaraan Medium Bus Type J 05123 CC lebih murah dibanding Big Bus J 08E-UF,namun dari segi perawatan bus Medium Bus Type J $05123 \mathrm{CC}$ lebih boros dan lebis besar biayanya.

b. Dari hasil pembahasan analisis data komponen BOK, didapat BOK Medium Bus Type J 05123 CC lebih kecil dibanding BOK Big Bus J 08E-UF. Yang berarti biaya operasional yang harus dikeluarkan untuk Medium Bus Type J 05123 CC lebih efisien dan ekonomis dibanding Big Bus J 08E-UF.

\section{DAFTAR PUSTAKA}

[1] Departemen Pekerjaan Umum (2005) Pedoman Konstruksi Pembangunan: Perhitungan Biaya Operasi Kendaraan.

[2] Khristy, C Jotin, And B Kent Lall (2003) Dasar-Dasar Rekayasa Tranportasi. Penerbit Erlangga, Jakarta.

[3] Rahman, Rahmatang. Analisa Biaya Operasi Kendaraan (Bok) Angkutan Umum Antar Kota Dalam Propinsi Rute Palu - Poso. Jurnal Rekayasa Dan Manajemen Transportasi.

[4] Ramadhan, Zulkifli (2014). Analisis perhitungan dan perbandingan biaya operasional kendaraan (BOK) Bus Rapid Transit (BRT) Trasnmusi jenis mercedes benz OH-1521 dan Hino RK8-235. Jurnal Teknik Sipil dan Lingkungan. 